\title{
Seasonal abundance and daily flying activity of black flies (Diptera: Simuliidae) attracted to human baits in Doi Inthanon National Park, northern Thailand
}

\author{
Wej Choochote ${ }^{1)}$, Hiroyuki TakaokA ${ }^{2), 3)}$, Masako FukudA ${ }^{2), 3)}$, \\ Yasushi Otsuka ${ }^{2)}$, Chiharu AokI ${ }^{2)}$ and Nobuoki Eshima ${ }^{4)}$ \\ 1) Department of Parasitology, Faculty of Medicine, Chiang Mai University, Chiang Mai, 50200, Thailand \\ ${ }^{2)}$ Department of Infectious Disease Control, Faculty of Medicine, Oita University, \\ Yufu City, Oita, 879-5593, Japan \\ 3) Division of Epidemiology, Culture, and Communication, Institute of Scientific \\ Research, Oita University, Yufu City, Oita, 879-5593, Japan \\ 4) Department of Medical Information Analysis, Faculty of Medicine, Oita University, \\ Yufu City, Oita, 879-5593, Japan
}

(Received: 30 August 2005; Accepted: 24 October 2005)

\begin{abstract}
The seasonal abundance and daily flying activity of adult black flies were investigated at four different altitudes $(400 \mathrm{~m}, 860 \mathrm{~m}, 1,360 \mathrm{~m}$ and 2,460 m) in Doi Inthanon National Park, northern Thailand. Collections were carried out at each altitude twice a month from 0600 to 1800 hours from August 2003 to July 2004, and adult black flies attracted to a human bait were captured by a hand net. The numbers of black flies collected were 2,599,24,010, 7,996 and 4,496 at altitudes of $400 \mathrm{~m}, 860 \mathrm{~m}$, $1,360 \mathrm{~m}$ and $2,460 \mathrm{~m}$, respectively. A total of 39,101 adult black flies comprising 39,060 females, 37 males and 4 sex mosaics of 23 species of the genus Simulium Latreille s. 1. were identified. Simuliid species composition and abundance varied according to altitude. Three species, i.e., S. (Gomphostilbia) asakoae Takaoka and Davies, S. (Simulium) rufibasis Brunetti and S. (S.) nigrogilvum Summers, were regularly attracted to a human bait in this order of predominance. Simulium (G.) asakoae was captured from low to medium altitudes, while $S$. (S.) rufibasis was captured mostly at high altitude, and $S$. (S.) nigrogilvum at medium altitudes. The seasonal patterns in abundance of all these predominant species varied among species even at the same altitudes and also by altitude even within the same species. 'Daily flying activities of these three predominant species differed in patterns and in peak hours by altitudes, by species, and also by seasons. Those of $S$. (G.) asakoae were similar in all seasons showing essentially a bimodal pattern with the first peak early in the morning and the second in the late afternoon, or vice versa; while $S$. (S.) nigrogilvum and $S$. (S.) rufibasis showed uni-, bi- and trimodal daily flying patterns. Five species, i.e., S. (G.) asakoae, $S$. (S.) chamlongi Takaoka and Suzuki, S. (S.) nigrogilvum, S. (S.) nodosum Puri and S. (S.) rufibasis, were confirmed to bite human beings.
\end{abstract}

Key words: black fly, seasonal abundance, diurnal flying activity, man-biting species, Simuliidae, northern Thailand

\section{INTRODUCTION}

Black flies or Simuliidae (Diptera) are one of the medically and veterinary important groups of small bloodsucking in- sects. The bites of adult females cause a wide range of problems for humans and other vertebrates. Some species serve as vectors of several pathogens, e.g., filarial nematodes of the genus Onchocerca to man and cattle, genus Dirofilaria to bear, 
and blood protozoans of the genus Leucocytozoon to birds (Crosskey, 1990; Kettle, 1990). Moreover, black-fly bites can cause very serious problems, since they frequently inflict pain, localized swelling and inflammation accompanied by intense irritation that lasts for several days or even weeks. Repeated biting by some species can cause headaches, fevers, swollen lymph glands and aching joints (Service, 1996).

In the Oriental region, several manbiting simuliid species have been incriminated, e.g., Simulium (Simulium) indicum Becher, which is widely distributed at the southern foot of the Himalayas, from Pakistan in the west, through India and Nepal, to Myanmar and southern China in the east (Lewis, 1974; Datta, 1992); S. (S.) asishi Datta, S. (S.) himalayense Puri, S. (S.) nodosum Puri and S. (Gomphostilbia) tenuistylum Datta in India (Datta, 1992); and S. (S.) japonicum Matsumura in the Ryukyu Islands, Japan (Takaoka, 1977). Recently, S. (S.) nigrogilvum Summers and S. (S.) nodosum, which are both anthropophilic and zoophilic, were reported to be naturally infected with the third-stage larvae of different unknown filarial species in northern Thailand (Takaoka et al., 2003; Fukuda et al., 2003).

In Thailand, at least 56 black-fly species have been recorded, and classified into six subgenera in the genus Simulium Latreille s. 1., i.e., Asiosimulium Takaoka and Choochote, Deviesellum Takaoka and Adler, Gomphostilbia Enderlein, Montisimulium Rubtsov, Nevermannia Enderlein, and Simulium Latreille s. str. (Takaoka and Choochote, 2004a, b, c, 2005a, b, c, d, e, f, g, h, i). Apart from these, significant progress has been made only in the population cytogenetic (Kuvangkadilok et al., 1998, 1999b, c, 2003) and molecular genetic studies (Otsuka et al., 2003), and in the studies on natural transmission of zoonotic filariae by the Thai simuliids (Takaoka et al., 2003; Fukuda et al., 2003).

Little is known about the biological and/or ecological aspects of black flies, particularly the species found in Doi Inthanon National Park, northern Thailand, except for a report of larval distribution of 16 species from 12 localities in this area (Kuvangkadilok et al., 1999a). It has been generally accepted for a long time that black flies are vicious pests of humans and other vertebrates in Doi Inthanon National Park. They are found in large numbers and cause irritation to indigenous people, tourists and domestic animals. In view of their important role as a vicious biter, and lack of biological and/or ecological information, a more thorough study was needed. Therefore, the seasonal abundance and daily flying activity of adult black flies attracted to a human bait at four different altitudes in Doi Inthanon National Park are described below. Also, the proven man-biting simuliid species from this area are reported for the first time.

\section{Materials And Methods}

Study sites: Four sites with different altitudes in Doi Inthanon National Park, Chiang Mai province, northern Thailand, i.e., Site 1, Mae Klang Waterfall (altitude $400 \mathrm{~m}$ ); Site 2, the Fire Control Center (altitude $860 \mathrm{~m}$ ); Site 3, Siribhume Waterfall (altitude 1,360 m); and Site 4, Ang Ka (altitude $2,460 \mathrm{~m}$ ), were selected for adult collections (Fig. 1A, B).

Adult collections: Collections were carried out twice a month at each site starting from 0600 to 1800 hours, from August 2003 to July 2004. Adult black flies trying to bite or flying around a human bait positioned approximately 5 meters from perennial breeding streams were captured by a catcher using a handnet (diameter $30 \mathrm{~cm}$, depth $60 \mathrm{~cm}$ ). The collection time for each hour was divided into $50 \mathrm{~min}$ catching and $10 \mathrm{~min}$ resting. Adult black flies caught hourly were preserved in separate vials filled with $80 \%$ ethanol, and brought to the laboratory. The species were identified using the morphological keys of Takaoka and 

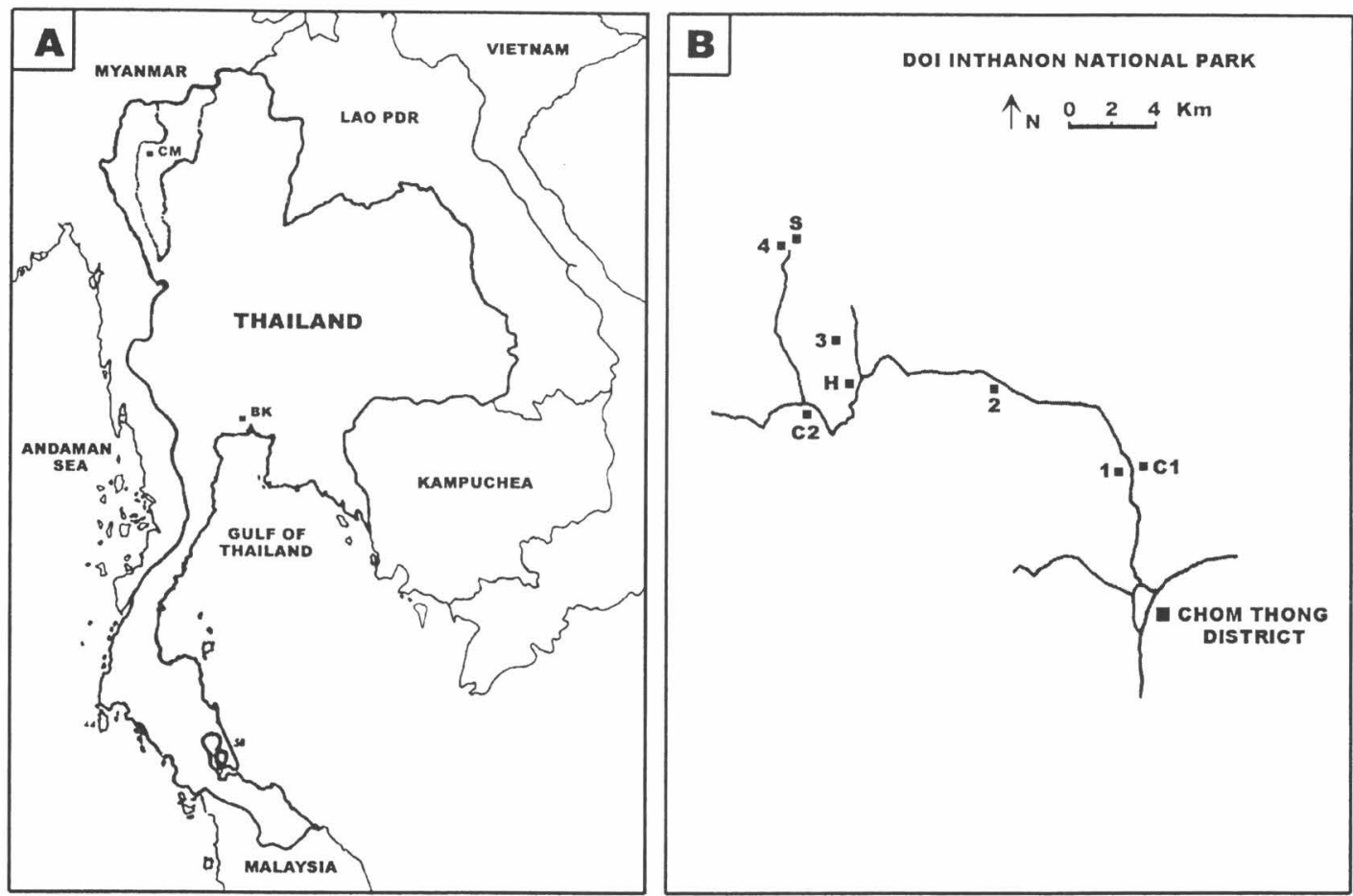

Fig. 1. A, Map of Thailand showing Doi Inthanon National Park, Chiang Mai province, Thailand (CM), where black fly collections were performed at four sites. Chiang Mai is situated at a latitude of $18^{\circ} 47^{\prime} \mathrm{N}$ and longitude $98^{\circ} 59^{\prime} \mathrm{E}$ in northern Thailand, and approximately 581 kilometers away from the capital city, Bangkok (BK), central Thailand; B, Map showing the location of four sites used for collections of adult black flies, numbers 1 to 4 indicate Site 1 (400 m in altitude), Site 2 (860 m in altitude), Site 3 (1,360 $\mathrm{m}$ in altitude) and Site 4 (2,460 $\mathrm{m}$ in altitude), respectively.

Choochote (2004b). The mean total numbers of adult females of each species per day calculated from the two-day collections of each month were used as the mean monthly numbers of adult females to express seasonal flying activities of three predominant species. On the other hand, daily flying activities of three predominant species were evaluated when the total numbers of adult females of the respective species caught per day exceeded 50. On the basis of the data obtained from the two-day collections of each month, their patterns (i.e., unimodal, bimodal and trimodal) together with the major and/or second peak activity hours were determined. For reference, air temperature and relative humidity were measured every 10 minutes from 0600 to 1800 hours by a digital thermometer and hygrometer, respectively during the experiment. The mean monthly air temperature and relative humidity are represented by the mean daily air temperature and relative humidity calculated from the data obtained from the two-day collections of each month. Following the Thai Meteorological Department, the year is climatically divided into three seasons on the basis of rainfall and air temperature values, i.e., hot season (mid February to mid May), rainy season (mid May to mid October), and dry-cool season (mid October to mid February), which are shown in Fig. 2, together with monthly changes in rainfall, air temperature and humidity measured from August 2003 to July 2004 by the Northern Meteorological Center, situated in Muang district, Chinag Mai province, at altitude of $312 \mathrm{~m}$. 


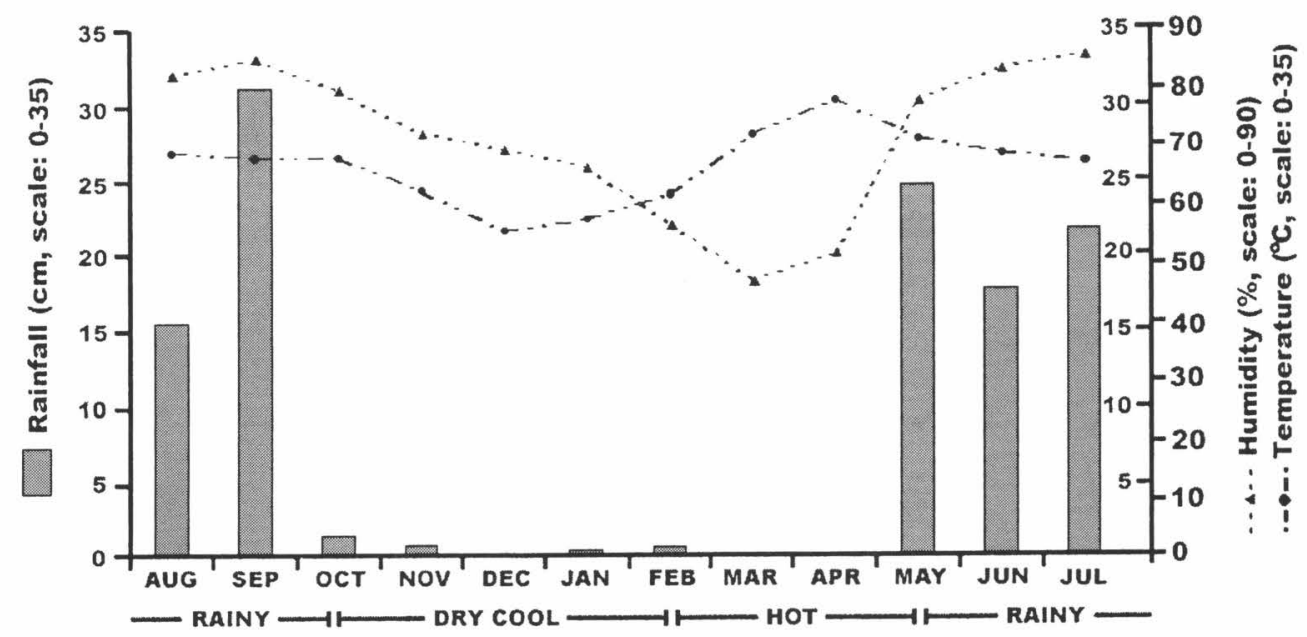

Fig. 2. Three seasons in Thailand, together with mean monthly rainfalls, air temperatures and humidities measured from August 2003 to July 2004 by Northern Meteorological Center, Muang district, in Chiang Mai province (altitude $312 \mathrm{~m}$ ).

Man biting habit was determined by occasional observations of adult females being allowed to feed on blood of a human bait (first author) at four different altitudes.

\section{RESUlts}

Species captured, in descending order of dominance, at four different altitudes in Doi Inthanon National Park, are shown in Table 1. A total of 39,101 adult black flies comprising 39,060 females (including 138 gravid females), 37 males and 4 sex mosaics of 23 species belonging to 4 subgenera (Gomphostilbia, Montisimulium, Nevermannia, Simulium s. str.) of the genus Simulium s. 1. were captured. Fourteen of 23 species, i.e., S. (S.) rufibasis, S. (S.) setsukoae Takaoka and Choochote, $S$. $(G$.) burtoni Takaoka and Davies, S. (G.) inthanonense Takaoka and Suzuki, S. (S.) rudnicki Takaoka and Davies, S. (S.) siripoomense Takaoka and Saito, S. (S.) barnesi Takaoka and Suzuki, S. (S.) yuphae Takaoka and Choochote, S. (N.) aureohirtum Brunetti, S. (N.) feuerborni Edwards, S. (S.) suchariti Takaoka and Choochote, S. (M.) surachaii Takaoka and Choochote, S. (S.) crocinum Takaoka and Choochote and $S$. (N.) caudisclerum Taka- oka and Davies, were captured for the first time using a human bait. Three species, i.e., S. (G.) asakoae, S. (S.) rufibasis and S. (S.) nigrogilvum, were regularly attracted to the human bait in order of predominance. The most predominant species, $S$. (G.) asakoae, was captured from low (400 $\mathrm{m})$ to medium $(860 \mathrm{~m} ; 1,360 \mathrm{~m})$ altitudes (Site 1 to Site 3 ) in air temperatures ranging from 10.9 to $44.0^{\circ} \mathrm{C}$. Its flying activities were observed in air temperatures between $11.1^{\circ} \mathrm{C}$ and $39.9^{\circ} \mathrm{C}$. Total numbers of $2,425,22,522$ and 6,757 were captured at altitudes of $400 \mathrm{~m}, 860 \mathrm{~m}$ and $1,360 \mathrm{~m}$, respectively. Simulium (S.) rufibasis, the second predominant species, totaling 4,090 , were captured mostly at high altitude $(2,460 \mathrm{~m})$ in low air temperatures $\left(7.0-21.3^{\circ} \mathrm{C}\right)$ throughout the year. Its flying activities were recorded between $8.0^{\circ} \mathrm{C}$ and $21.3^{\circ} \mathrm{C}$. The third predominant species, S. (S.) nigrogilvum, was captured mostly from medium altitudes (Sites 2 and 3 ) in air temperatures ranging from 10.9 to $35.8^{\circ} \mathrm{C}$. Its flying activities were confirmed between $13.4^{\circ} \mathrm{C}$ and $29.8^{\circ} \mathrm{C}$. Total numbers of 1,102 and 827 were captured at Site 2 and Site 3, respectively. The following five species were captured in satisfactory numbers at respective altitudes: $S$. $(G$.) chumpornense Takaoka and Kuvangka- 
Table 1. Numbers of adult black flies collected on a human bait at four different altitudes in Doi Inthanon National Park, northern Thailand from August 2003 to July 2004.

\begin{tabular}{|c|c|c|c|c|c|c|c|c|}
\hline \multirow{2}{*}{ Simulium spp. } & \multicolumn{4}{|c|}{ Site (Altitude, m) } & \multirow{2}{*}{ Total } & \multirow{2}{*}{ Female } & \multirow{2}{*}{ Male } & \multirow{2}{*}{ Sex mosaic } \\
\hline & $1(400)$ & $2(860)$ & $3(1,360)$ & $4(2,460)$ & & & & \\
\hline S. (G.) asakoae & 2,425 & 22,522 & 6,757 & 1 & 31,705 & 31,667 & 34 & 4 \\
\hline S. (S.) rufibasis* & 0 & 0 & 7 & 4,090 & 4,097 & 4,097 & 0 & 0 \\
\hline S. (S.) nigrogilvum & 2 & 1,102 & 827 & 2 & 1,933 & 1,933 & 0 & 0 \\
\hline S. (S.) doipuiense & 0 & 2 & 214 & 5 & 221 & 221 & 0 & 0 \\
\hline S. (S.) setsukoae* & 0 & 0 & 7 & 203 & 210 & 210 & 0 & 0 \\
\hline S. $(G$.) chumpornense & 159 & 21 & 26 & 0 & 206 & 206 & 0 & 0 \\
\hline S. (S.) fenestratum & 0 & 3 & 10 & 189 & 202 & 202 & 0 & 0 \\
\hline S. (S.) nakhonense & 5 & 150 & 12 & 0 & 167 & 165 & 2 & 0 \\
\hline S. (S.) chamlongi & 0 & 30 & 95 & 1 & 126 & 126 & 0 & 0 \\
\hline S. (S.) nodosum & 0 & 58 & 17 & 0 & 75 & 75 & 0 & 0 \\
\hline S. (G.) siamense & 4 & 47 & 3 & 0 & 54 & 54 & 0 & 0 \\
\hline S. (G.) burtoni* & 0 & 25 & 3 & 0 & 28 & 28 & 0 & 0 \\
\hline S. (G.) inthanonense* & 4 & 19 & 2 & 1 & 26 & 26 & 0 & 0 \\
\hline S. (S.) rudnicki* & 0 & 23 & 2 & 0 & 25 & 25 & 0 & 0 \\
\hline S. (S.) siripoomense* & 0 & 4 & 4 & 0 & 8 & 8 & 0 & 0 \\
\hline S. (S.) barnesi* & 0 & 0 & 4 & 0 & 4 & 4 & 0 & 0 \\
\hline S. (S.) yuphae* & 0 & 4 & 0 & 0 & 4 & 4 & 0 & 0 \\
\hline S. $(N$.$) aureohirtum*$ & 0 & 0 & 3 & 0 & 3 & 3 & 0 & 0 \\
\hline S. $(N$.$) feuerborni*$ & 0 & 0 & 2 & 0 & 2 & 2 & 0 & 0 \\
\hline S. (S.) suchariti* & 0 & 0 & 0 & 2 & 2 & 2 & 0 & 0 \\
\hline S. (M.) surachaii* & 0 & 0 & 0 & 1 & 1 & 1 & 0 & 0 \\
\hline S. (S.) crocinum* & 0 & 0 & 1 & 0 & 1 & 1 & 0 & 0 \\
\hline S. $(N$.$) caudisclerum*$ & 0 & 0 & 0 & 1 & 1 & 0 & 1 & 0 \\
\hline Total & 2,599 & 24,010 & 7,996 & 4,496 & 39,101 & 39,060 & 37 & 4 \\
\hline No. of species collected & 6 & 14 & 19 & 11 & 23 & 22 & 3 & 1 \\
\hline
\end{tabular}

* Species collected for the first time using a human bait.

Subgenera: G., Gomphostilbia; M., Montisimulium; N., Nevermannia; S., Simulium s. str.

dilok at $400 \mathrm{~m}, \mathrm{~S}$. (S.) nakhonense Takaoka and Suzuki at $860 \mathrm{~m}$, S. (S.) doipuiense Takaoka and Choochote at $1,360 \mathrm{~m}$, and $S$. (S.) setsukoae and $S$. (S.) fenestratum Edwards at $2,460 \mathrm{~m}$. The other 12 species, i.e., S. (S.) chamlongi Takaoka and Suzuki, S. (S.) nodosum, S. (G.) siamense Takaoka and Suzuki, S. (G.) burtoni, S. (G.) inthanonense, S. (S.) rudnicki, S. (S.) siripoomense, S. (S.) barnesi, S. (S.) yuphae, S. (N.) aureohirtum, S. (N.) feuerborni and $S$. (S.) crocinum, were captured mostly at altitudes of $860 \mathrm{~m}$ and $1,360 \mathrm{~m}$, whereas $S$. (S.) suchariti, S. (M.) surachaii and $S$. (N.) caudisclerum were captured only at $2,460 \mathrm{~m}$.

Man-biting habit was confirmed for five species, i.e., S. (G.) asakoae, S. (S.) chamlongi, S. (S.) nigrogilvum, S. (S.) nodosum and $S$. (S.) rufibasis. Among these, S. (S.) nigrogilvum and $S$. (S.) rufibasis tended to bite and feed without hesitation once they landed on the skin of the human bait. Simulium (G.) asakoae seemed to take more time to land on the skin before it began to bite and was more easily disturbed while feeding as compared to the other species.

Mean monthly numbers of $S$. (G.) asakoae, $S$. (S.) nigrogilvum and $S$. (S.) rufibasis at four different altitudes expressing the seasonal abundance are demonstrated in Figs. 3, 4 and 5. For S. (G.) asakoae at Site $1(400 \mathrm{~m})$, the mean monthly numbers were relatively high (115-284) during the dry-cool season (from mid October to mid February), with the first peak in January and the second one in October (Fig. 3). It is interesting to note that 
Site 1

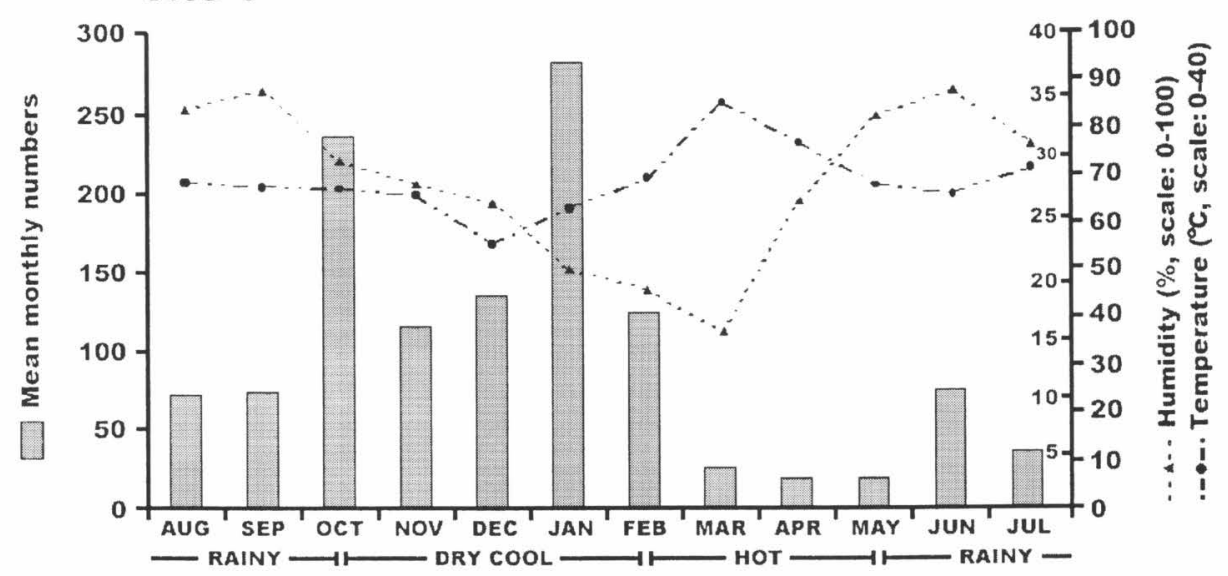

Site 2

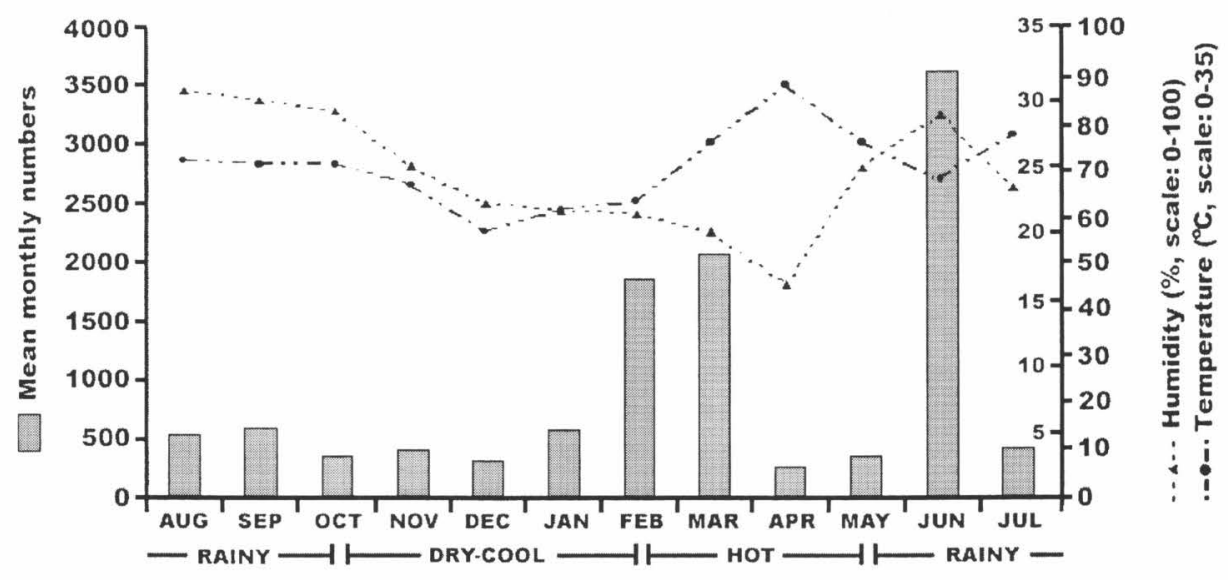

Site 3

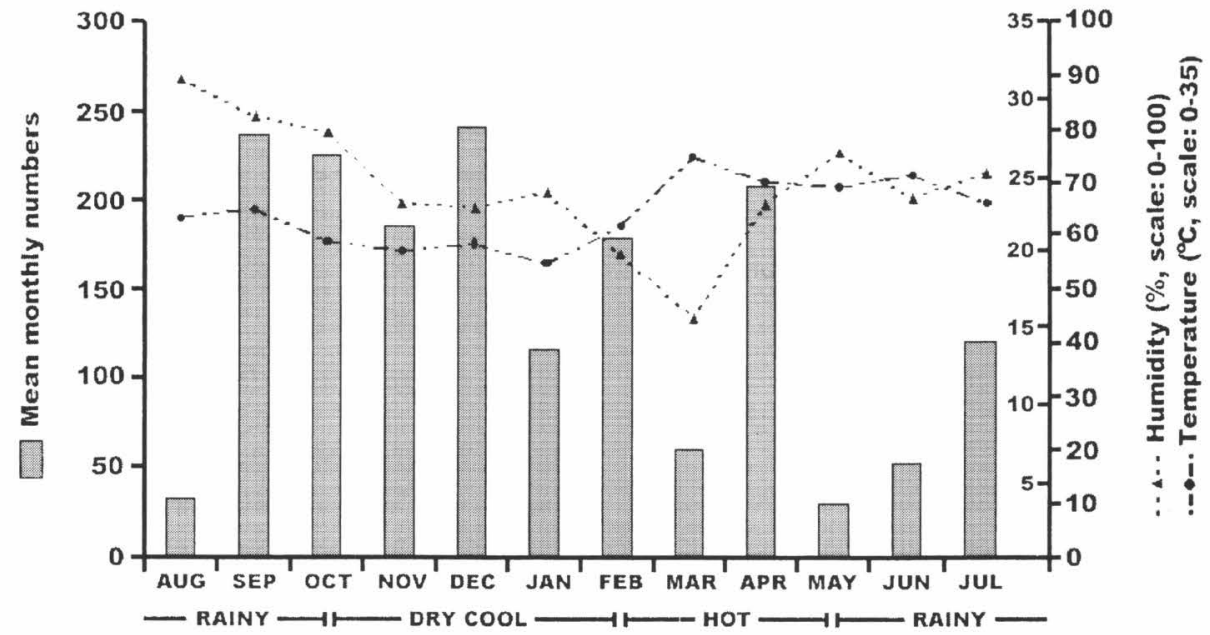

Fig. 3. Seasonal changes in abundance of $S$. (G.) asakoae attracted to a human bait at Site 1 (400 m), Site $2(860 \mathrm{~m})$ and Site $3(1,360 \mathrm{~m})$. 
Site 2

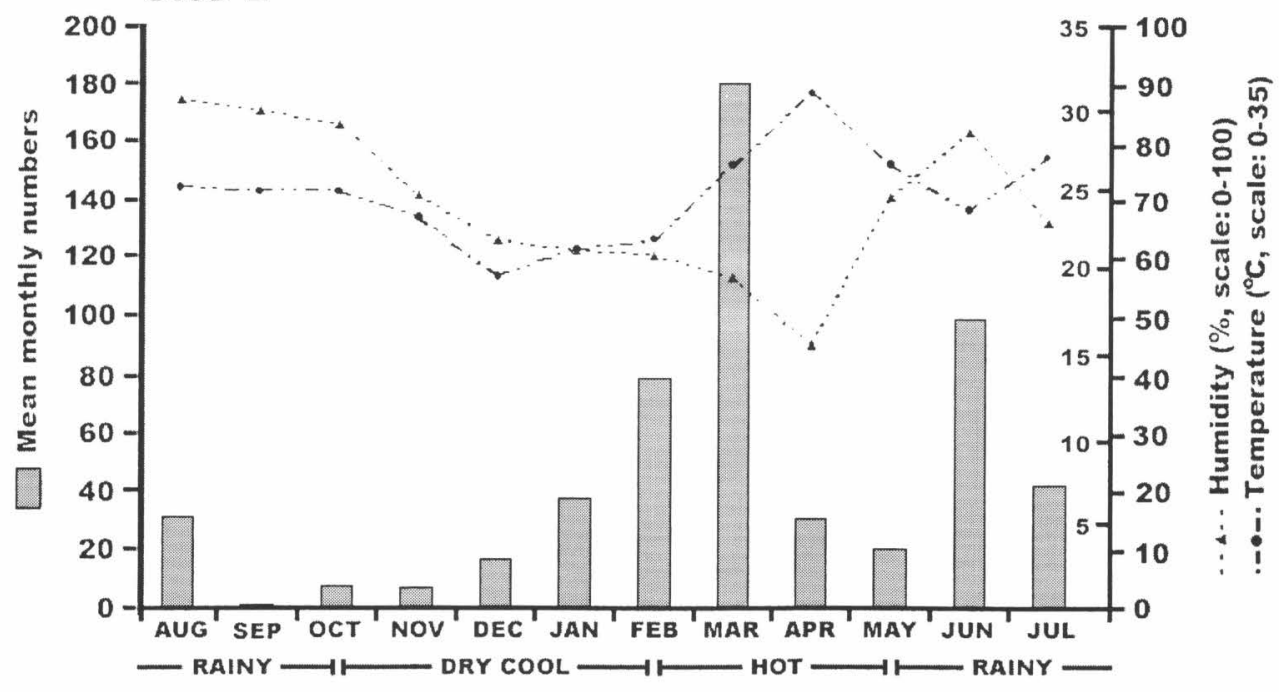

Site 3

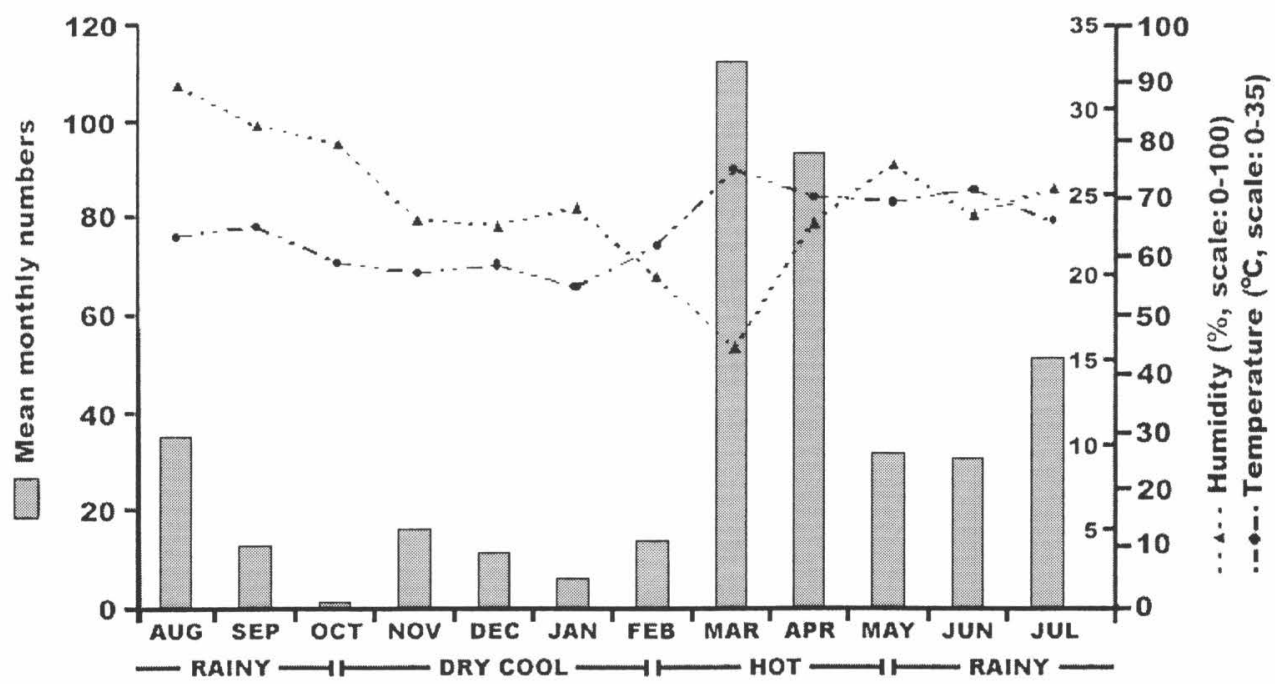

Fig. 4. Seasonal changes in abundance of S. (S.) nigrogilvum attracted to a human bait at Site 2 (860 m) and Site $3(1,360 \mathrm{~m})$.

during this season the mean rainfall was extremely low $(0-1.28 \mathrm{~cm})$, extending to April of the hot season. From March to September, the mean monthly numbers were relatively low, ranging from 18.5 to 75.5. At Site $2(860 \mathrm{~m})$, the total number of collections $(22,522)$ was approximately three and nine times higher than those collected at Site $3(1,360 \mathrm{~m})$ and Site 1 (400 $\mathrm{m})$. High numbers were obtained through- out the whole-year or all three seasons with mean monthly numbers ranging from 225.5 to $3,598.5$ (Fig. 3). Two peaks were clearly observed, i.e., the first peak in the early rainy season (June), and the second one in the early to mid hot season (February and March). At Site 3 (1,360 m), appreciable mean monthly numbers were recovered throughout the year, ranging from 61 to 483, though relatively high 


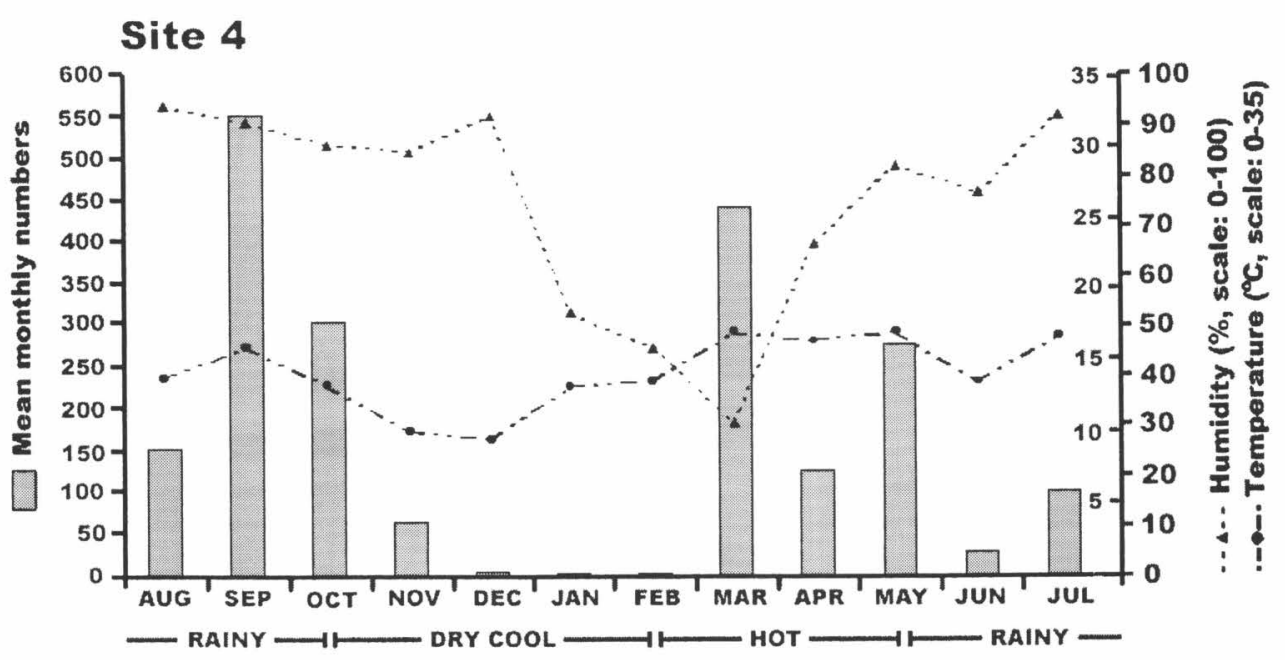

Fig. 5. Seasonal change in abundance of S. (S.) rufibasis attracted to a human bait at Site $4(2,460 \mathrm{~m})$.

numbers were continuously seen from the late rainy season (September) to the mid hot season (April) except those in January and March (Fig. 3).

For S. (S.) nigrogilvum, nearly similar patterns of mean monthly numbers were observed at both Site $2(860 \mathrm{~m})$ and Site 3 $(1,360 \mathrm{~m})$ (Fig. 4). There were two peaks, of which the first peak was in March of the hot season and the second one was in June (at $860 \mathrm{~m}$ ) or July (at $1,360 \mathrm{~m}$ ) of the mid rainy season. In the late rainy and drycool seasons, the mean monthly numbers recovered from both sites were very low and erratic (1-37.5 at Site 2 and 1-16 at Site 3).

A clear bimodal seasonal abundance was seen for S. (S.) rufibasis at Site $4(2,460$ $\mathrm{m})$, i.e., the first peak was in the late rainy season (September) with a mean monthly number of 551.5, and the second peak was in the early hot season (March) with a mean monthly number of 438.5 (Fig. 5). The mean monthly numbers during the dry-cool season from December to February were extremely low (2-5.5).

The patterns and peak hours of daily flying activities of the two most predominant species at Sites 1-4 are shown in Table 2. At Site $1(400 \mathrm{~m})$, S. (G.) asakoae showed a clear bimodal pattern with the first peak in the morning and the second peak in the late afternoon in the dry-cool season except in November and January when the first and second peaks were reversed. On the other hand, it showed a unimodal pattern with its peak in the early morning in the rainy season except for a bimodal pattern in one of the two collection days in August. The mean hourly air temperatures measured in the representative month of each season were $20.5-33.5^{\circ} \mathrm{C}$ in February, $23.2-27.9^{\circ} \mathrm{C}$ in June, and $15.2-31.3^{\circ} \mathrm{C}$ in December.

At Site $2(860 \mathrm{~m}), S$. (G.) asakoae also showed similar bimodal patterns throughout the year except in April of the hot season and July of the rainy season, when it showed a unimodal pattern with its peak in the early morning. In the bimodal pattern, the first and second peaks both in the morning and afternoon cycles seemed to shift by seasons i.e., in the dry-cool season, peaks in the morning cycle were delayed one to three hours while those in the afternoon cycle advanced one hour as compared with those in the rainy season. Simulium (S.) nigrogilvum, the second dominant species at Site 2, showed a bimodal pattern with its peaks in the early morning and in the late afternoon in February and March. However, this species also showed a unimodal pattern of daily flying activities with its peak in the late after- 
Table 2. Daily flying activity patterns of three predominant simuliid species in two-collection days of each month at Sites 1-4 in Doi Inthanon National Park, northern Thailand.

\begin{tabular}{|c|c|c|c|c|c|c|c|c|c|c|c|c|}
\hline \multirow{3}{*}{$\begin{array}{l}\text { Sites [Altitude] } \\
\text { Species }\end{array}$} & \multicolumn{12}{|c|}{ Months and seasons } \\
\hline & 1 & 2 & 3 & 4 & 5 & 6 & 7 & 8 & 9 & 10 & 11 & 12 \\
\hline & \multicolumn{2}{|c|}{ Dry-cool } & \multicolumn{2}{|c|}{ Hot } & & \multicolumn{4}{|c|}{ Rainy } & \multicolumn{3}{|c|}{ Dry-cool } \\
\hline $\begin{array}{l}\text { Site } 1[400 \mathrm{~m}] \\
\text { S. asakoae }\end{array}$ & $\begin{array}{c}\text { B } \\
17(7) \\
\text { B } \\
17(8)\end{array}$ & $\begin{array}{c}\text { B } \\
8(17) \\
\text { B } \\
8(17)\end{array}$ & - & - & - & $\begin{array}{c}\mathrm{U} \\
7 \\
\mathrm{U} \\
7\end{array}$ & - & $\begin{array}{c}\text { B } \\
6(15) \\
\mathrm{U} \\
6\end{array}$ & $\begin{array}{l}\mathrm{U} \\
7 \\
-\end{array}$ & $\begin{array}{c}\text { B } \\
7(17) \\
\text { B } \\
7(17)\end{array}$ & $\begin{array}{c}B \\
17(7) \\
B \\
7(17)\end{array}$ & $\begin{array}{c}\text { B } \\
8(16) \\
B \\
8(17)\end{array}$ \\
\hline \multicolumn{13}{|l|}{ Site $2[860 \mathrm{~m}]$} \\
\hline \multirow[t]{4}{*}{ S. asakoae } & B & B & B & $\mathrm{U}$ & B & B & $\mathrm{U}$ & B & B & B & B & B \\
\hline & $16(9)$ & $9(17)$ & $17(8)$ & 6 & $7(17)$ & $6(17)$ & 6 & $7(17)$ & $6(17)$ & $6(13)$ & $7(16)$ & $16(7)$ \\
\hline & B & B & B & $\mathrm{U}$ & B & B & $\mathrm{U}$ & B & B & B & B & B \\
\hline & $8(16)$ & $9(17)$ & $17(8)$ & 6 & $7(17)$ & $6(17)$ & 6 & $7(17)$ & $6(16)$ & $6(17)$ & $8(16)$ & $16(8)$ \\
\hline \multirow[t]{2}{*}{ S. nigrogilvum } & - & $\begin{array}{c}\text { B } \\
7(16)\end{array}$ & $\begin{array}{c}\text { B } \\
7(17)\end{array}$ & - & - & - & - & - & - & - & - & - \\
\hline & $\begin{array}{r}\mathrm{U} \\
16\end{array}$ & - & $\begin{array}{c}\text { B } \\
16(7)\end{array}$ & - & & - & - & - & - & - & - & - \\
\hline \multirow{5}{*}{$\begin{array}{l}\text { Site } 3[1,360 \mathrm{~m}] \\
\text { S. asakoae }\end{array}$} & & & & & & & & & & & & \\
\hline & B & B & B & B & - & B & $\mathrm{U}$ & - & B & B & B & B \\
\hline & $17(8)$ & $17(8)$ & $7(17)$ & $17(7)$ & & $6(16)$ & 6 & & $6(16)$ & $6(17)$ & $17(8)$ & $16(8)$ \\
\hline & B & B & B & B & B & B & $\mathrm{U}$ & B & B & B & B & B \\
\hline & $17(7)$ & $17(9)$ & $17(7)$ & $15(7)$ & $7(17)$ & $6(16)$ & 6 & $6(17)$ & $6(17)$ & $6(17)$ & $8(17)$ & $16(8)$ \\
\hline \multirow[t]{3}{*}{ S. nigrogilvum } & - & - & B & $\mathrm{T}$ & B & - & - & - & - & - & - & - \\
\hline & & & $16(7)$ & $17(7)$ & $14(7)$ & & & & & & & \\
\hline & - & - & $\begin{array}{c}\text { B } \\
7(17)\end{array}$ & $\begin{array}{c}\text { B } \\
15(6)\end{array}$ & - & $\begin{array}{c}\text { B } \\
17(7)\end{array}$ & $\begin{array}{c}\text { B } \\
17(8)\end{array}$ & - & - & - & - & - \\
\hline \multirow{5}{*}{$\begin{array}{l}\text { Site } 4[2,460 \mathrm{~m}] \\
\text { S. rufibasis }\end{array}$} & & & & & & & & & & & & \\
\hline & - & - & $\mathrm{U}$ & B & $\mathrm{T}$ & - & - & - & $\mathrm{T}$ & $\mathrm{U}$ & - & - \\
\hline & & & 9 & $10(16)$ & $7(10)$ & & & & $9(17)$ & 15 & & \\
\hline & - & - & $\mathrm{U}$ & B & $\mathrm{T}$ & - & B & $\mathrm{U}$ & $\mathrm{T}$ & B & U & - \\
\hline & & & 9 & $10(16)$ & $9(17)$ & & $7(17)$ & 16 & $6(16)$ & $16(7)$ & 13 & \\
\hline
\end{tabular}

$\mathrm{U}, \mathrm{B}$, and $\mathrm{T}$ mean unimodal, bimodal and trimodal flying activity patterns, respectively Numbers mean major peak time (e.g., 6, 0600-0700 hours).

Numbers in parenthesis mean secondary peak time (e.g., 6, 0600-0700 hours).

Bars indicate 'not assessed for flying activity patterns' due to small number less than 50 flies collected per day.

noon in one of the two collection days in January, which differs from that of $S$. $(G$.) asakoae showing a bimodal pattern with its first peak in the early morning. The mean hourly air temperatures measured at Site 2 were $18.8^{-}-30.6^{\circ} \mathrm{C}$ in March, 20.9$26.1^{\circ} \mathrm{C}$ in June and $14.0-27.6^{\circ} \mathrm{C}$ in December.

At Site 3, S. (G.) asakoae showed a clear bimodal pattern with the first peak in the late afternoon in the dry-cool and hot seasons, and in the early morning in the rainy season. In July of the rainy season, it showed a unimodal pattern with its peak in the early morning, as in the same month at Site 2. Bimodal patterns with the first peak in the late afternoon were also obtained for $S$. (S.) nigrogilvum collected at Site 2 in the hot and early rainy seasons except in April when a trimodal pattern was seen. The mean hourly air temperatures measured at Site 3 were 


\section{Rainy (July 27)}

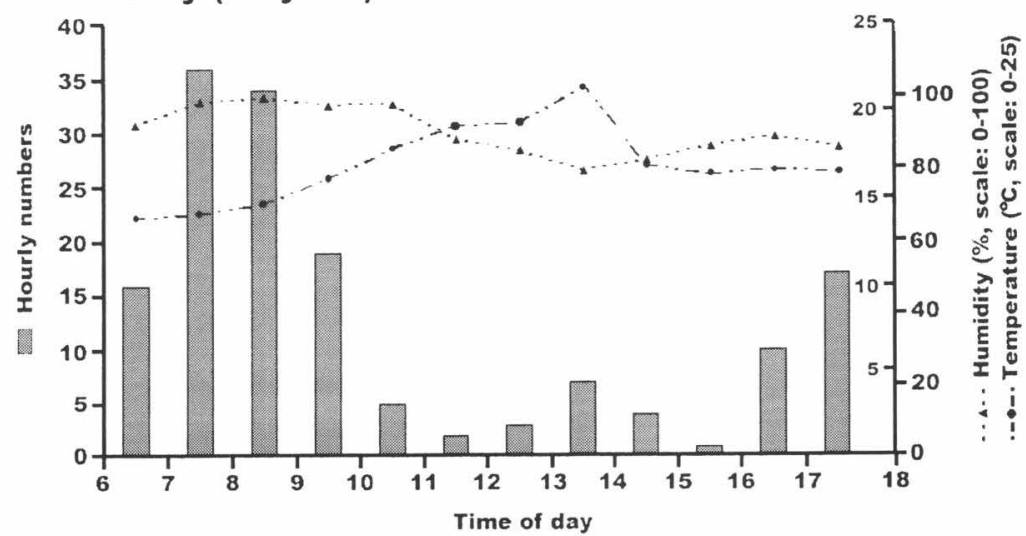

Rainy (September 21)

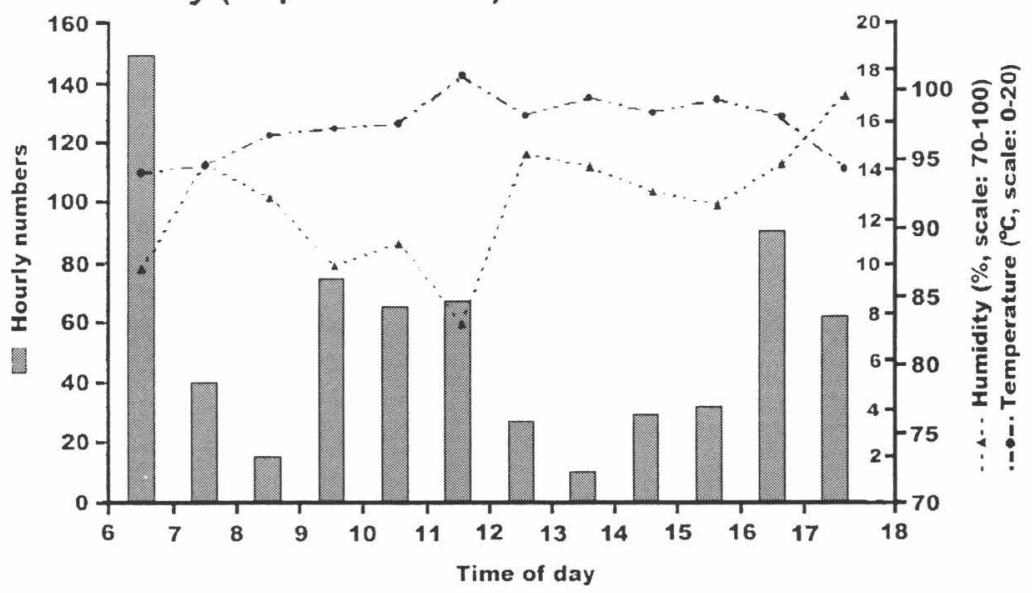

Dry-cool (November 30)

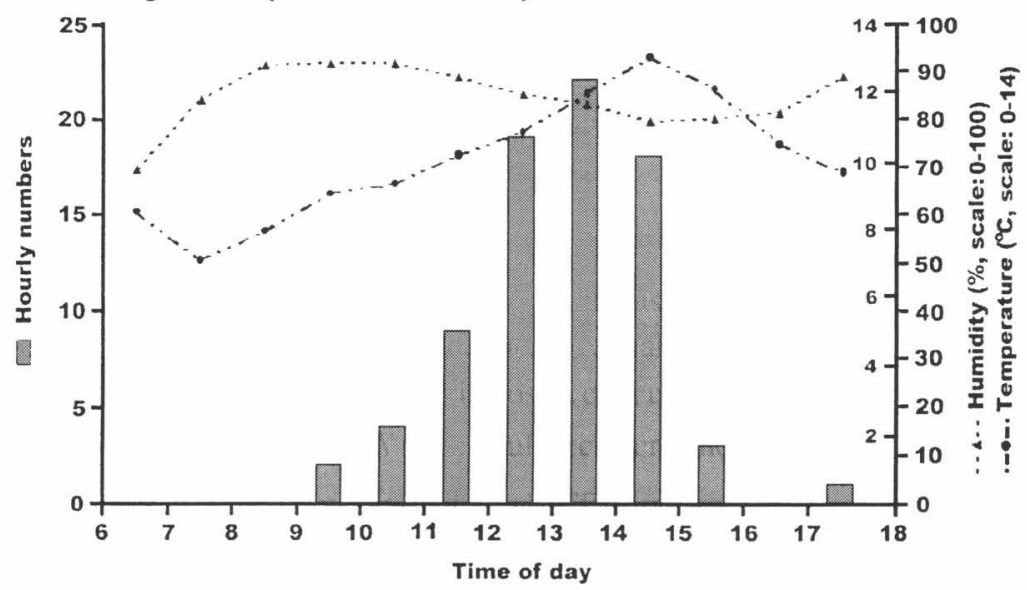

Fig. 6. Different daily flying activity patterns of $S$. (S.) rufibasis attracted to a human bait from 0600 to 1800 hours at Site $4(2,460 \mathrm{~m})$ : bimodal pattern in July, trimodal pattern in September, and unimodal pattern with its peak early in the afternoon in November; all representative examples were based upon the data obtained from a single collection day. 
$17.9-30.1^{\circ} \mathrm{C}$ in March, $19.9-28.0^{\circ} \mathrm{C}$ in June and $12.0-27.0^{\circ} \mathrm{C}$ in December.

At Site $4, S$. (S.) rufibasis, the most predominant species, most remarkably varied in daily flying patterns having all three patterns, i.e., uni-, bi-, and trimodal patterns even in the same seasons (e.g., Fig. 6). And also there is a clear difference in the peak hour even in the same unimodal patterns by seasons, i.e., 0900-1000 hours in the hot season, 1500-1600 hours or 16001700 hours in the rainy season, 1300-1400 hours in the dry-cool season. The mean hourly air temperatures measured at Site 4 were $12.4-20.6^{\circ} \mathrm{C}$ in March, $13.7-18.0^{\circ} \mathrm{C}$ in September, and $7.7-11.6^{\circ} \mathrm{C}$ in November.

\section{Discussion}

To the best of our knowledge, this study is the first attempt to identify the black fly species attracted to or biting humans, and to measure their seasonal abundance and daily flying activity in the famous tourist area of Doi Inthanon National Park, northern Thailand.

It is clear from this study that Doi Inthanon National Park with well conserved natural forests is rich in diversity of simuliid fauna in terms of species number and variety, though only adult samples collected on a human bait were examined. The high number (23) of simuliid species collected, in part due to the altitude-specific species composition, corresponds to $41.1 \%$ of the total number of species recorded from Thailand. The richness in species variety is also evidenced by the fact that they are classified into the four phylogenetically different subgenera (Table 1). This may be a reflection of richness in various types of clean perennial and/or seasonal flowing watercourses from tiny trickles to large rivers well developed from low to high altitudes in this park. Black flies of various subgenera usually differ in their preference for the aquatic sites that are suitable for breeding of the preimaginal stages.
As already mentioned, most man-biting species belong to the subgenus Simulium s. str. in the Oriental region. Our results are striking in that nine of the 23 species belong to three different subgenera (i.e., five to Gomphostilbia, three to Nevermannia, and one to Montisimulium), all of which are thought to be ornithophilic (Crosskey, 1990). In particular, it is noteworthy that the most predominant species in low and medium altitudes was $S$. $(G$.) asakoae.

It is clarified that simuliid species composition and abundance varied according to altitude (Table 1). Three species, i.e., S. (G.) asakoae, S. (S.) nigrogilvum, and $S$. (S.) rufibasis, were regularly attracted to human bait, the first two being captured mostly in medium altitudes, and the last one mostly in high altitude. All these three predominant species as well as two minor ones, i.e., S. (S.) chamlongi and S. (S.) nodosum, have been proven to bite humans in this park. However it should be noted that $S$. (S.) nigrogilvum and $S$. (S.) rufibasis are the most vicious man-biter in medium and high altitudes, respectively. Three other species, in particular $S$. $(G$.) asakoae, are at most a hesitant man-biter, according to our field observations.

Data on the seasonal abundance of the three predominant species in this park are firstly demonstrated in Figs. 3, 4 and 5. Surprisingly, considerable numbers of $S$. (G.) asakoae were collected at an altitude of $860 \mathrm{~m}$ throughout the year, with mean fly numbers per day of 225.5-3,598.5 (Fig. 3 , Site 2). The actual maximum total number of $S$. (G.) asakoae recorded was 4,149 in one of the two collection days of June. The seasonal patterns in abundance of $S$. (G.) asakoae were distinct but markedly differed by altitudes (Fig. 3), while those of $S$. (S.) nigrogilvum were nearly similar at two altitudes (Fig. 4) but its seasonal pattern obtained at an altitude of $1,360 \mathrm{~m}$ was different from that of $S$. $(G$.) asakoae at the same altitude (Figs. 3 and 4). Thus, the seasonal patterns in abundance appear to vary by altitude even 
within the same species and also among species even at the same altitudes in the same park. The similar results were reported on the seasonal abundance of adult black flies in a Guatemalan endemic area of human onchocerciasis (Takaoka, 1981, 1982). Adult female populations of three anthropophilic species, S. (Psilopelmia) ochraceum Walker, S. (S.) metallicum Bellardi and S. (S.) horacioi Okazawa and Onishi, fluctuated differently from one another, when compared even at the same location; and those of $S$. (P.) ochraceum also differed from one location to another. These different seasonal patterns of abundance were presumed to be associated with seasonal variations in the availability of streams suitable for the breeding of the three species which choose differently their aquatic sites (Takaoka, 1981). The seasonal patterns of $S$. (G.) asakoae, S. (S.) nigrogilvum and $S$. (S.) rufibasis obtained in the present study may be at least partially explained by the seasonal variations in the availability of the larval streams. However, this should be confirmed in the future studies because we do not have any information on the biology of these three species including their preference for the types of breeding watercourses, duration of larval development, and nutrition. The seasonal abundance of adult black flies attracted to humans is not always correctly reflected by that of the larval population, which would be reflected to a certain extent by the quantity and stability of larval streams. The other factors concerned include the preference of adult females for host animals as a blood-meal source, the availability of other animals, the distance from the oviposition and pupal sites to collecting sites, and climate (air temperature, humidity, rainfall, light intensity, wind, etc.).

Results obtained on the seasonal abundance of adult females were derived from a one-year survey. The data are insufficient to be analysed in relation to three distinct seasons in this park (hot, rainy and dry-cool); however the yearly pattern in abundance of $S$. (S.) rufibasis obtained at an altitude of $2,460 \mathrm{~m}$, which is characterized by its adult flying activities occurring only during the hot and rainy seasons and lacking during the dry-cool season (Fig. 5), appears to be related to seasonal variations of air temperatures. More data will be needed to determine the seasonality in abundance of all these three predominant species in this park and to clarify their relationship to the three seasons.

Daily flying activities of the three predominant species examined in this study differed in patterns and peak hours to some extent by altitudes even in the same species, by species compared even at the same site and on the same day, and also remarkably by seasons in the same species, as shown in Table 2. It is apparent that $S$. (G.) asakoae usually shows bimodal patterns with its peaks either in the early morning or in the late afternoon, and rarely unimodal patterns with the peak in the early morning in certain months of the rainy season at three altitudes, and also varies to some extent in the peak hours from one season to another even at the same site. It is remarkable that both $S$. $(S$.) nigrogilvum and S. (S.) rufibasis showed three patterns, i.e., uni-, bi-, and trimodal (Fig. 6). So far, bimodal or unimodal pattern of the daily biting activities was observed for other species, e.g., bimodal pattern in S. (Trichodagmia) guianense Wise and S. (Psaroniocompsa) oyapockense Floch and Abonnenc in the humid Amazon between Venezuela and Brazil (Grillet et al., 2005) and S. (Notolepria) exiguum Roubaud s. 1. in Ecuador (Vieira et al., 2005), and unimodal in S. (Edwardsellum) yahense Vajime and Dunbar in Liberia (Davis et al., 1994), S. (Ps.) incrustatum Luz in the humid Amazon between Venezuela and Brazil (Grillet et al., 2005) and $S$. (P.) quadrivittatum Loew in Ecuador (Vieira et al., 2005). The daily patterns of flying activities of adult black flies attracted to human bait are also influenced by many factors such as those 
mentioned above. In our preliminary analyses (unpublished data), it is at least suggested that the daily flying activity pattern of $S$. (S.) rufibasis in November of the dry-cool season at Site $4(2,460 \mathrm{~m})$ is positively associated with the mean hour1y air temperatures (Fig. 6).

During this one-year survey, a total of about two hundred biting midges and about a hundred of mosquitoes were also collected in particular in the late afternoon and/or early morning, but these were of negligible importance in comparison with the huge numbers of black flies caught in the present survey. It is proven that black flies are the most important man-biter during daytime in the Doi Inthanon National Park. It is hoped that the findings obtained in this study would be helpful as a baseline information for people living in, or visiting, this park to avoid the risk of being bitten by black flies.

\section{ACKNOWLEDGEMENTS}

The authors sincerely thank Mr. Surachai Tuamsomboon, Chief, Headquarters of Doi Inthanon National Park, Wildlife and Plant Conservation Department, Ministry of National Resources and Environment, for his permission to conduct this investigation inside the park. Our appreciation goes to Mr. Pramote Suwanpanit, Ms. Anuluck Junkum and Mr. Nikom Sittipanich for their assistance in the field. We are grateful to Dr. Motoyoshi Mogi, Faculty of Medicine, Saga University, Saga, Japan, and Dr. Lilian A. de las Llagas, Faculty of Public Health, University of the Philippines, Manila, Philippines, for their kindness in reading the manuscript and giving valuable comments. This work was financially supported by a Grant-in-Aid from Japan-US Medical Research Cooperation Program (for the fiscal years, 2003 and 2004).

\section{REFERENCES}

Crosskey, R.W. 1990. The Natural History of Blackflies. ix +711 pp., John Wiley \& Sons Ltd., Chichester.

Datta, M. 1992. An overview of the Simuliidae (Diptera) of West Bengal, India. J. Bengal Natur. Hist. Soc. New Series, 11: 41-62.

Davis, J. R., Wasserman, S. S. and Trpis, M. 1994. Diurnal biting activity and transmission of Onchocerca volvulus (Filariata: Onchocercidae) by Simulium yahense (Diptera: Simuliidae) in Liberia. J. Med. Entomol., 31: 217-224.

Fukuda, M., Choochote, W., Bain, O., Aoki, C. and Takaoka, H. 2003. Natural infections with filarial larvae in two species of black flies (Diptera: Simuliidae) in northern Thailand. Jpn. J. Trop. Med. Hyg., 31: 99-102.

Grillet, M. E., Villamizar, N. J., Cortez, J., Frontado, H. L., Escalona, M., Vivas-Martinez, S. and Basañez, M. G. 2005. Diurnal biting periodicity of parous Simulium (Diptera: Simuliidae) vectors in the onchocerciasis Amazonian focus. Acta Tropica, 94: 139-158.

Kettle, D. S. 1990. Medical and Veterinary Entomology. viii +725 pp., Colset Pte Ltd., Singapore.

Kuvangkadilok, C., Boonkemtong, C. and Phayuhasena, S. 1998. C-banding in polytene chromosomes of six Simulium species (Diptera: Simuliidae) from Doi Inthanon National Park, northern Thailand. J. Sci. Soc. Thailand, 24: 215-230.

Kuvangkadilok, C., Boonkemtong, C. and Phayuhasena, S. 1999a. Distribution of the larvae of blackflies (Diptera : Simuliidae) at Doi Inthanon National Park, northern Thailand. Southeast Asian J. Trop. Med. Pub. Health, 30: 328-337.

Kuvangkadilok, C., Boonkemtong, C., Phayuhasena, S. and Baimai, V. 2003. Larval polytene chromosome of black flies (Simulium) from Thailand. Genetica, 118: 69-81.

Kuvangkadilok, C., Phayuhasena, S. and Baimai, V. 1999b. Population cy togenetic studies on Simulium feuerborni Edwards (Diptera: Simuliidae) from northern Thailand. Genome, 42: 80-86.

Kuvangkadilok, C., Phayuhasena, S. and Boonkemtong, C. 1999c. Larval polytene chromosomes of five Simulium species (Diptera: Simuliidae) from Doi Inthanon National Park, northern Thailand. Cytologia, 64: 197-207.

Lewis, D. J. 1974. Man-biting Simuliidae (Diptera) of 
northern India. Israel. J. Entomol., 9: 23-53.

Otsuka, Y., Takaoka, H., Aoki, C. and Choochote, W. 2003. Phylogenetic analysis of the subgenus Himalayum within the genus Simulium s. 1. (Diptera: Simuliidae) using mitochondrial 16S rRNA gene sequences. Med. Entomol. Zool., 54: $113-120$.

Service, M. W. 1996. Medical Entomology for Students. 288 pp., Chapman \& Hall, London.

Takaoka, H. 1977. Studies on black flies of the Nansei Islands, Japan (Simuliidae; Diptera). III. On six species of the subgenus Simulium Latreille. Jpn. J. Sanit. Zool., 28: 193-217.

Takaoka, H. 1981. Seasonal occurrence of Simulium ochraceum, the principal vector of Onchocerca volvulus in the southeastern endemic area of Guatemala. Am. J. Trop. Med. Hyg., 30: 1121-1132.

Takaoka, H. 1982. Observations on the bionomics of larval and man-biting female populations of Simulium horacioi, a new potential vector of Onchocerca volvulus in Guatemala. Jpn. J. Trop. Med. Hyg., 10: 49-62.

Takaoka, H. and Choochote, W. 2004a. Two new species of Simulium (Simulium) (Diptera: Simuliidae) from Thailand. Jpn. J. Trop. Med. Hyg., 32: 3136.

Takaoka, H. and Choochote, W. 2004b. A list of and keys to black flies (Diptera: Simuliidae) in Thailand. Trop. Med. Health, 32: 189-197.

Takaoka, H. and Choochote, W. 2004c. Taxonomic notes on the griseifrons species-group of Simulium (Simulium) (Diptera: Simuliidae) in northern Thailand. Trop. Med. Health, 32: 311-327.

Takaoka, H. and Choochote, W. 2005a. Two new species of Simulium (Montisimulium) (Diptera: Simuliidae) from northern Thailand. Med. Entomol. Zool., 56: 21-31.

Takaoka, H. and Choochote, W. 2005b. A new subge- nus and a new species of Simulium s. 1. (Diptera: Simuliidae) from Thailand. Med. Entomol. Zool., 56: 33-41.

Takaoka, H. and Choochote, W. 2005c. A new species of Simulium (Simulium) (Diptera: Simuliidae) from Thailand. Med. Entomol. Zool., 56: 43-47.

Takaoka, H. and Choochote, W. 2005d. Two new species of Simulium (Simulium) (Diptera: Simuliidae) from northern Thailand. Med. Entomol. Zool., 56: 99-110.

Takaoka, H. and Choochote, W. 2005e. Two new species of Simulium Latreille (Diptera: Simuliidae) from northwestern Thailand. Med. Entomol. Zool., 56: $123-133$.

Takaoka, H. and Choochote, W. 2005f. A new species of Simulium (Simulium) from northern Thailand (Diptera: Simuliidae). Trop. Med. Health, 33: 95-101.

Takaoka, H. and Choochote, W. 2005g. Two new species of the griseifrons species-group of Simulium (Simulium) (Diptera: Simuliidae) in northern Thailand. Med. Entomol. Zool., 56: 219-235.

Takaoka, H. and Choochote, W. 2005h. Two new species of Simulium (Nevermannia) (Diptera: Simuliidae) from northern Thailand. Trop. Med. Health, 33: 133-141.

Takaoka, H. and Choochote, W. 2005i. Two new species of black flies (Diptera: Simuliidae) from northern Thailand. Med. Entomol. Zool., 56: 319-334.

Takaoka, H., Choochote, W., Aoki, C., Fukuda, M. and Bain, O. 2003. Black flies (Diptera: Simuliidae) attracted to humans and water buffalos and natural infections with filarial larvae, probably Onchocerca sp., in northern Thailand. Parasite, 10: 3-8.

Vieira, J. C., Brackenboro, L., Porter, C. H., Basañez, M. G. and Collins, R. C. 2005. Spatial and temporal variation in biting rates and parasite transmission potentials of onchocerciasis vectors in Ecuador. Trans. R. Soc. Trop. Med. Hyg., 99: 178-195. 